\title{
High frequency saltwater intrusion monitoring using borehole geophysical tools (SMD)
}

\author{
M. Baïsset ${ }^{1}$, D. Neyens ${ }^{1}$ \\ ${ }^{1}$ imaGeau, Montpellier, Hérault, FRANCE
}

\begin{abstract}
In February 2016, two remote controlled geophysical monitoring tools (SMD) have been installed for the first time in the Reunion Island. Settled into two piezometers drilled into a basaltic coastal aquifer, between the ocean and a production well, they allow the record of groundwater electrical conductivity $(\mathrm{ECw}) \operatorname{logs}$ on a $30 \mathrm{~min}$ basis. Thanks to those two tools, water operator continuously knows the shape and the position of the SWI as data are available online on a secured web application designed especially for SWI data management.

During the observation period a 5,15 m rise of SWI interface has been recorded. Knowing the average porosity, water table elevation and SWI interface position it is possible to estimate available fresh groundwater volume. Along a $1 \mathrm{~km}$ band between extraction well and the ocean, available fresh groundwater volume was found to be $1259000 \mathrm{~m} 3$ in June 2016. In June 2017, due to SWI progression this volume was found to be $777000 \mathrm{~m} 3$, that to say a $480000 \mathrm{~m} 3$ volume of freshwater replaced by brackish water.
\end{abstract}

SMD network will now be spread in the Reunion Island to improve coastal extraction well management knowing SWI shape and position on a high frequency basis.

\section{INTRODUCTION}

Due to a high demographic pressure, Reunion Island coastal aquifers are more and more subject to saltwater intrusion. Some coastal wells settled too close from the shore, in basaltic aquifers has to be abandoned, and new ones have to be drilled farthest from the coastline inducing financial damaged. As saltwater intrusion is increasing years after years on this island, it demands strong investments to precisely monitor fresh/saline interface position and its evolution according freshwater abstractions.

To achieve this objective, two remote controlled geophysical monitoring tools (SMD) have been installed into two piezometers settled in between the coastline and a production wells. They allow the record of hourly EC vertical logs to know on an hourly basis SWI interface position. Those geophysical tools are connected to a Web application (EMI) used by water operator to adapt fresh water extraction flow rate according to SWI.

\section{METHODS}

An SMD is an autonomous geophysical tool installed in a screened PVC piezometer used to constantly record water's electrical conductivity along the aquifer's vertical axis. It provides a real-time picture of the position and evolution of the saltwater intrusion available online on a web application. Two SMD have been installed in piezometers settled rescpectively at 125 $\mathrm{m}$ and $355 \mathrm{~m}$ from the Indian Ocean. They continuisly record EC logs every 30 min from 2 $\mathrm{m}$ absl to $27 \mathrm{~m}$ absl with a $100 \mathrm{~cm}$ vectival resolution. 


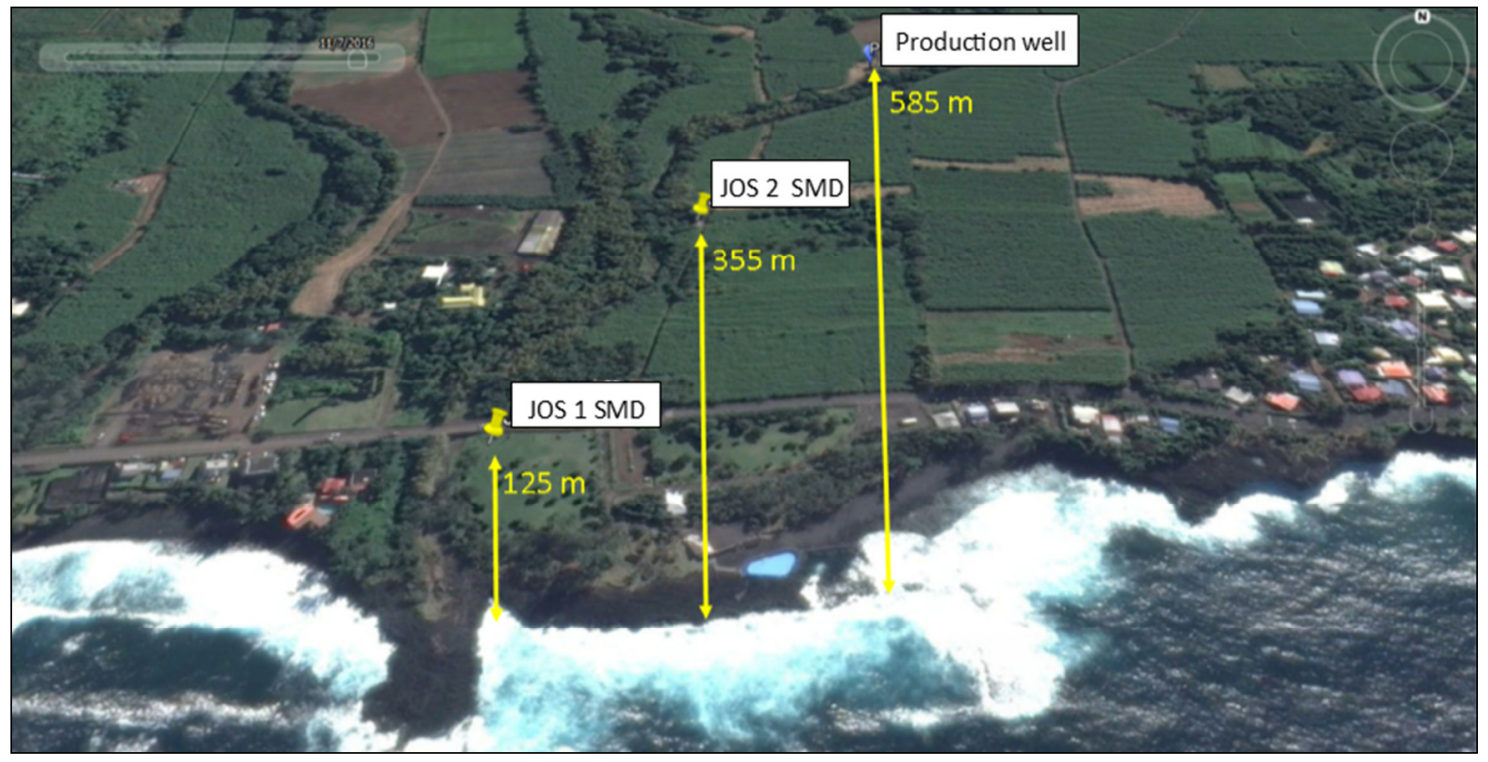

Figure 1. SMD localization named JOS1 and JOS2.

\section{RESULTS}

During the observation period, from February 2016 to July 2017, more than 20000 ECw logs have been recorded. This huge data amount allows analyzing SWI movement according different tide events, different rain events and different well extraction rates. Furthermore, it allows accurate calculation of monthly SWI interface mean position without artefact. Indeed, comparison of punctual logs do not allows apprehending low frequency SWI interface movements as they are not recorded in comparable tide event, rain event or swell event.

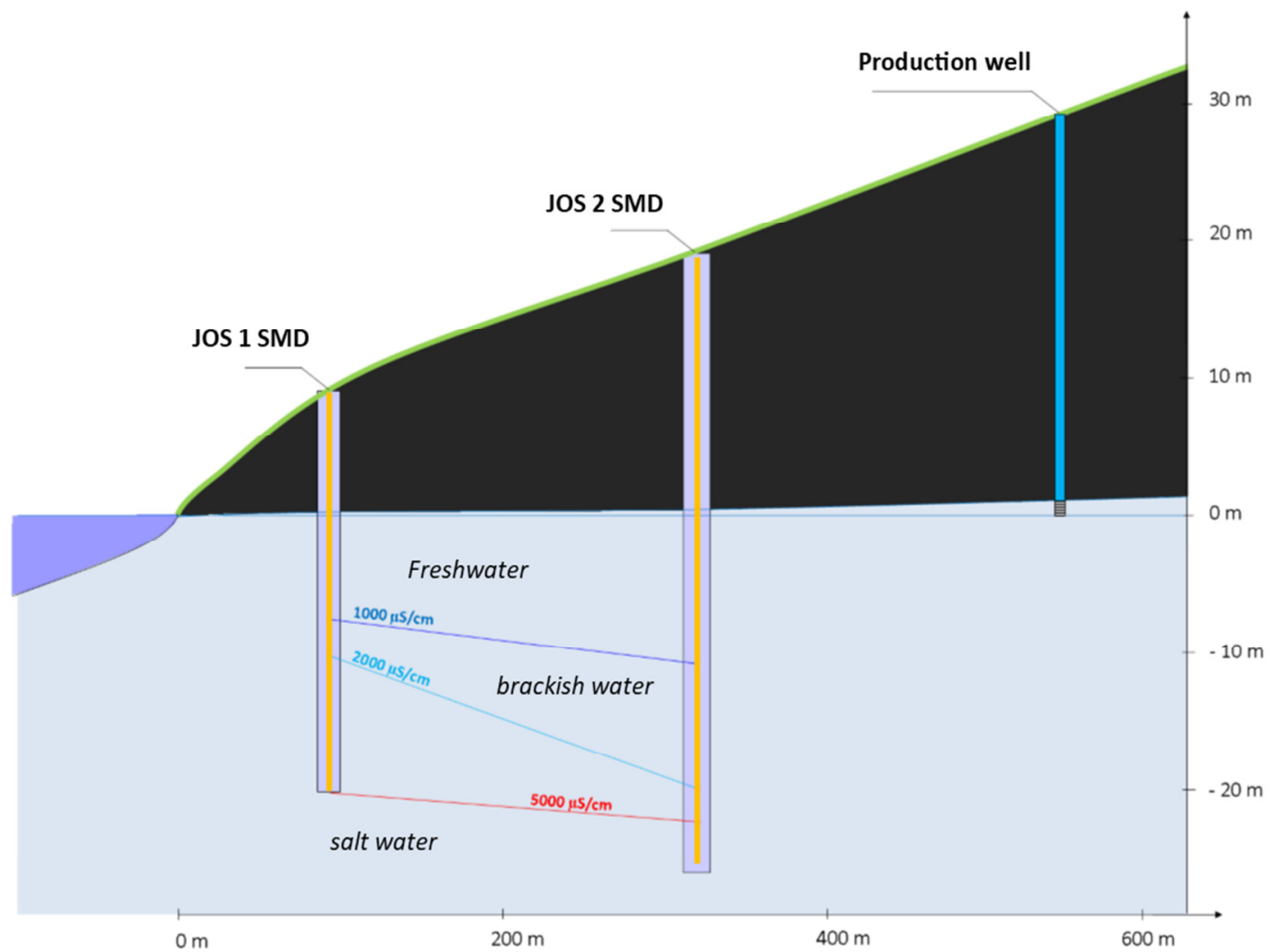

Figure 2. SWI shape measured by SMD. 
During the observation period at JOS $1 \mathrm{SMD}$, a $17 \%$ water conductivity increase has been recorded between the two dry seasons and a $22 \%$ water conductivity increase has been record between the two rainy seasons (Figure 3). Mean SWI interface position $(1 \mathrm{mS} / \mathrm{cm}$ limit) is going $30 \mathrm{~cm}$ up from June 2016 to June 2017.

At JOS 2 SMD located $200 \mathrm{~m}$ further inland, a 35\% water conductivity increase has been recorded between the two dry seasons and a $32 \%$ water conductivity increase has been recorded between the two rainy seasons (Figure 4). Mean SWI interface position $(1 \mathrm{mS} / \mathrm{cm}$ limit) is going 5,15 m up from June 2016 to June 2017.

Figure 5 presents comparison of SWI interface position between June 2016 and June 2017 (1 $\mathrm{mS} / \mathrm{cm}$ limit).

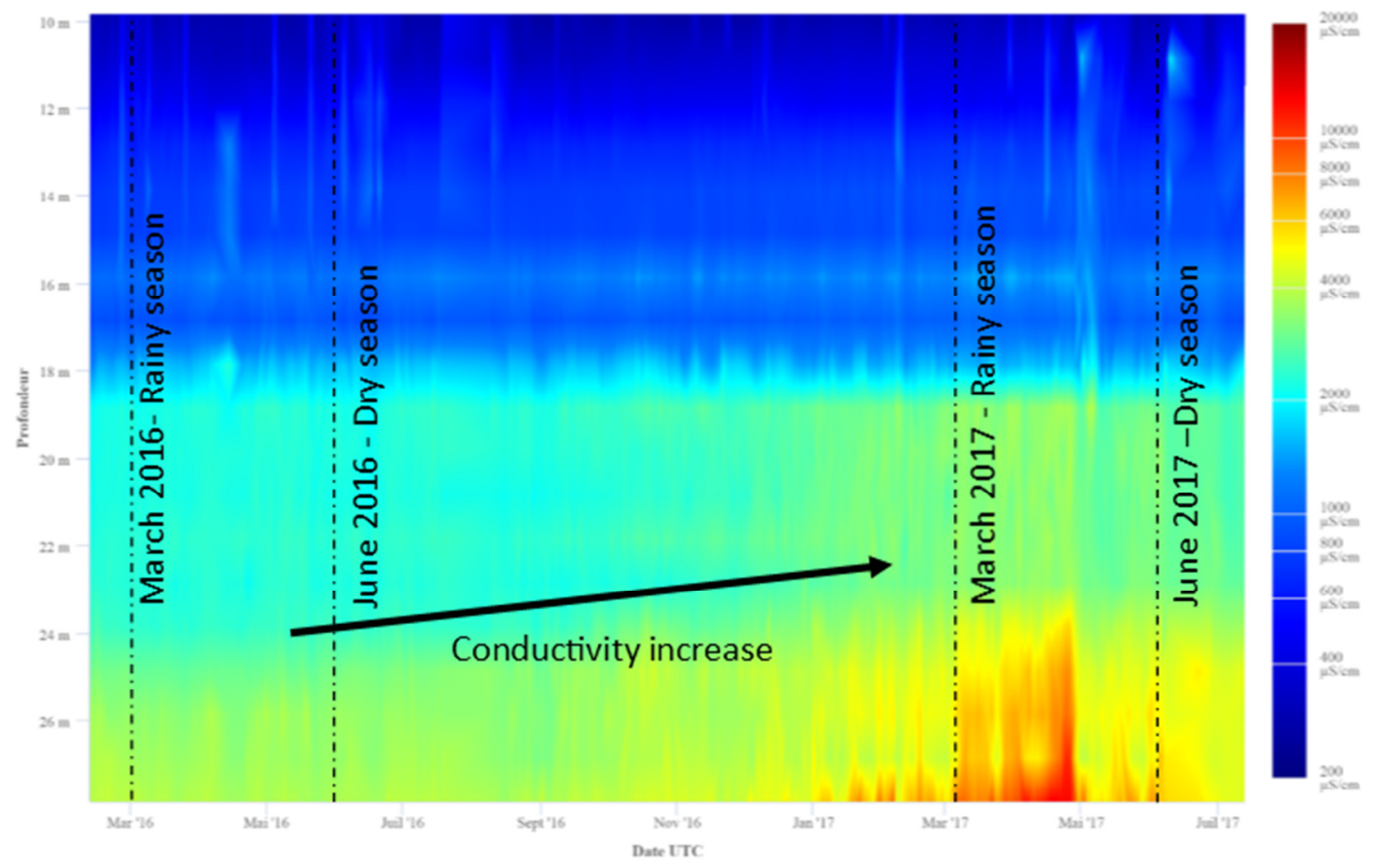

Figure 3. SMD logs measured by JOS 1 from July 2016 to July 2017.

Available fresh groundwater volume along $1 \mathrm{~km}$ coastline can thus be estimate knowing position of SWI interface $(1 \mathrm{mS} / \mathrm{cm}$ limit), water table elevation and mean porosity according the following equation:

Available fresh groundwater volume $=$ porosity $x$ (Area between Water table and SWI interface) $x 1000$

As water table elevation and SWI position are measured on a $30 \mathrm{~min}$ base, it is possible to know available fresh groundwater volume at this range of time. Monthly average can also be calculated to know the impact of SWI on available fresh groundwater amount. Figure 6 presents fresh groundwater volume balance from June 2016 to June 2017. This total balance gives a $480000 \mathrm{~m} 3$ volume of freshwater lost, replaced by brackish water during the observation period. 


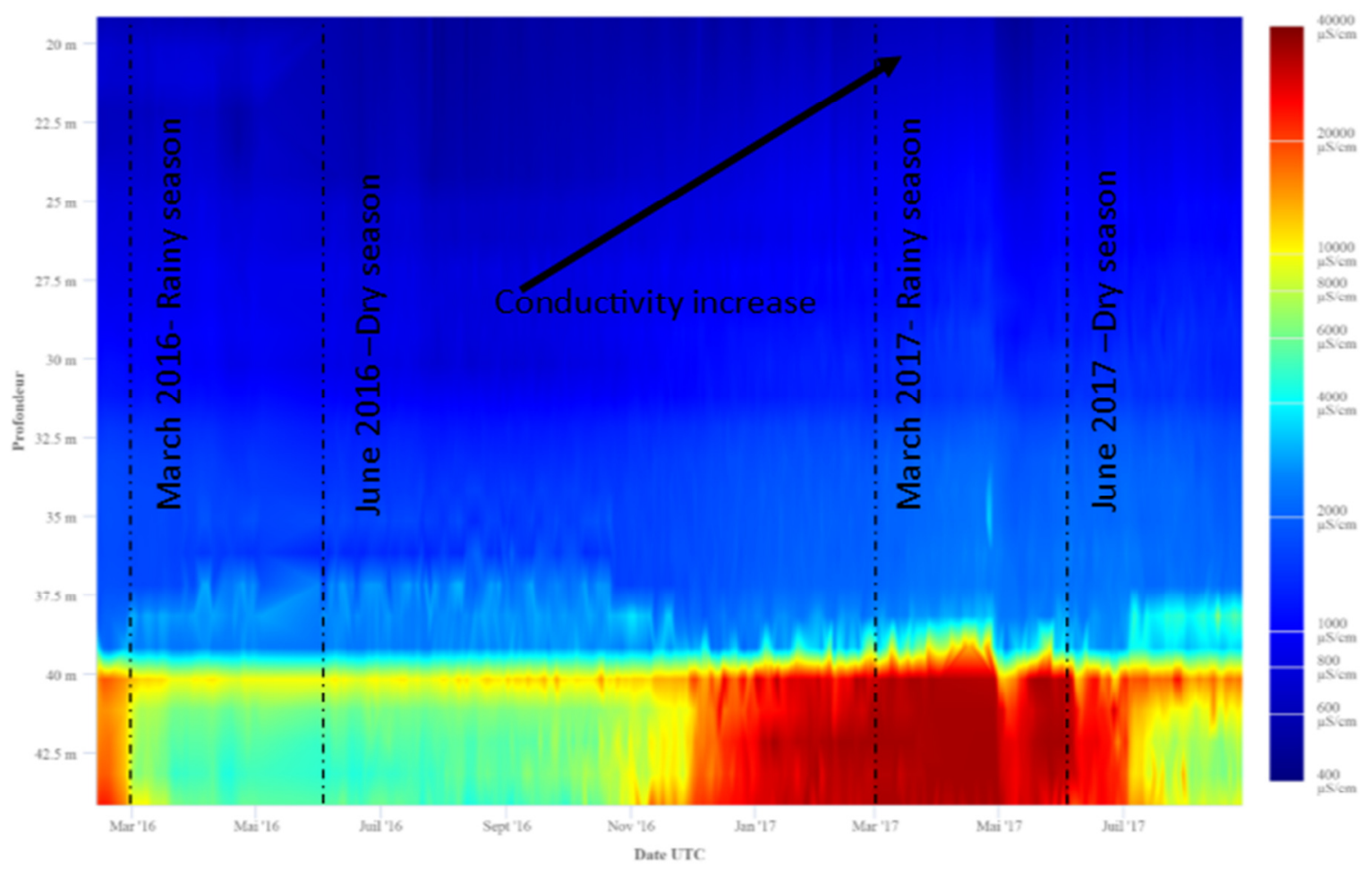

Figure 4. SMD logs measured by JOS 2 from July 2016 to July 2017.

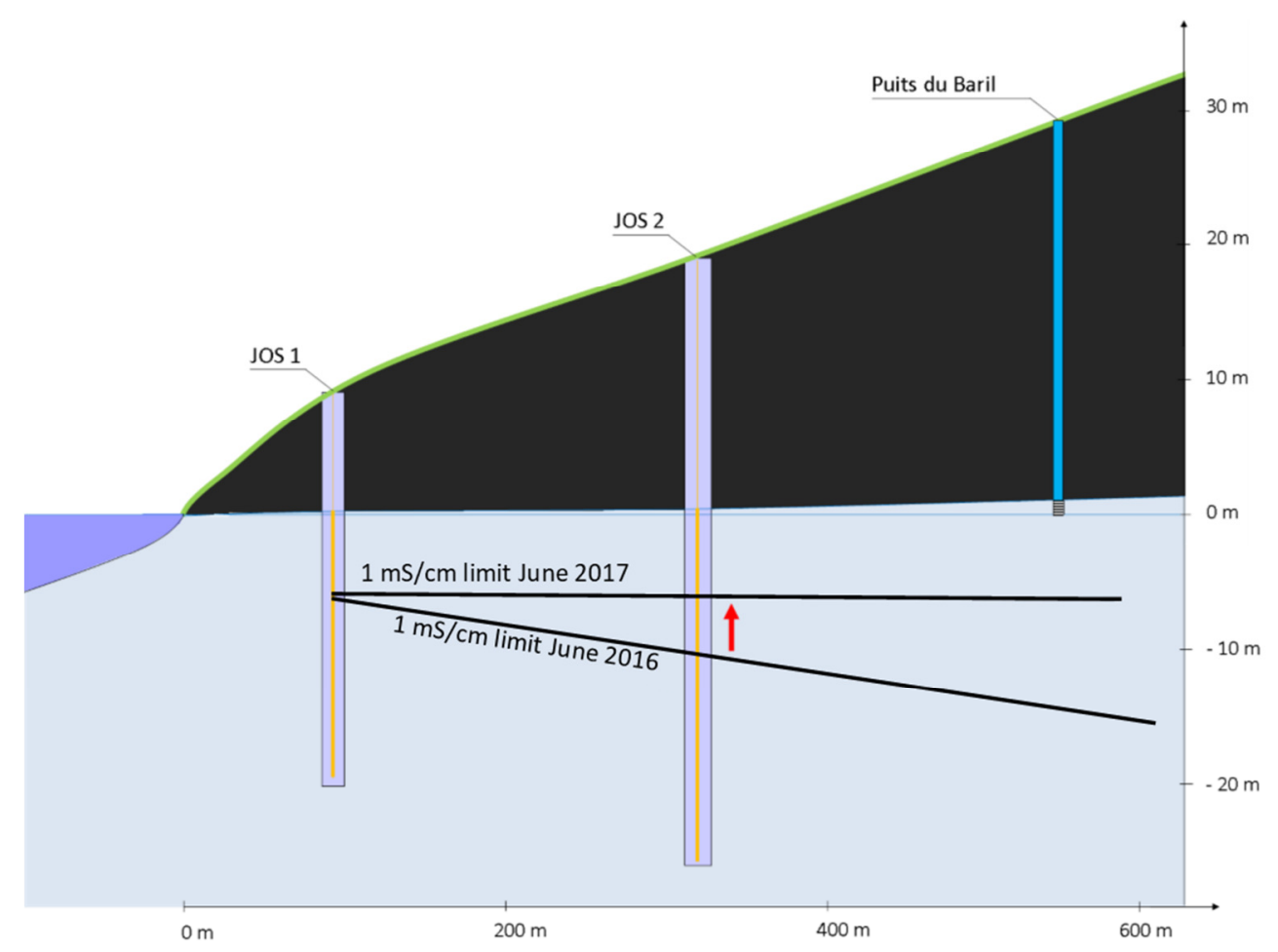

Figure 5. SWI interface position in June 2016 and June 2017 (1mS/cm limit) 


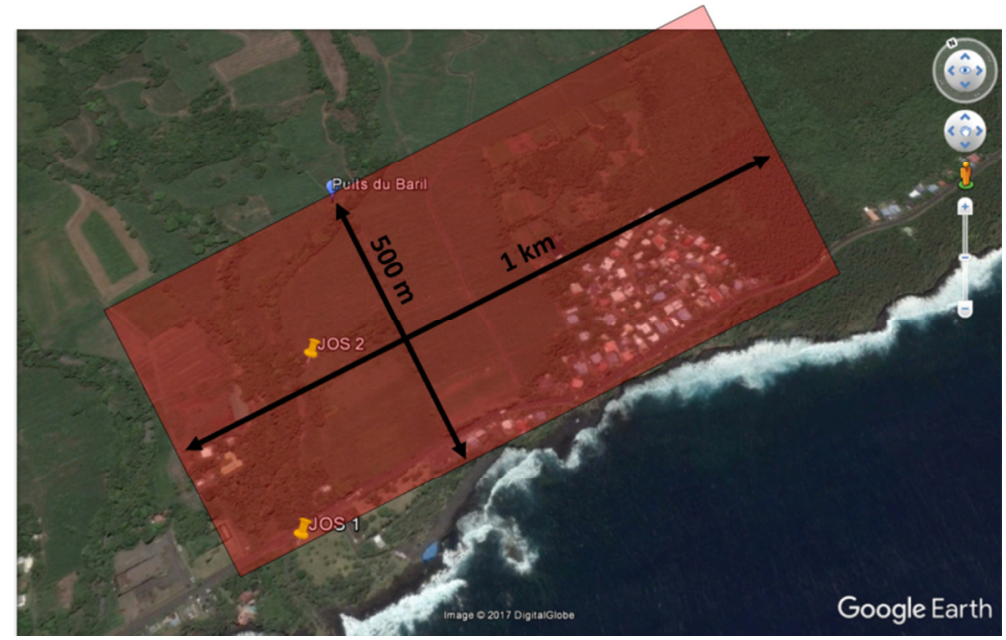

Figure 6. Calculation of available fresh groundwater on a $1 \mathrm{~km}$ coastline band.

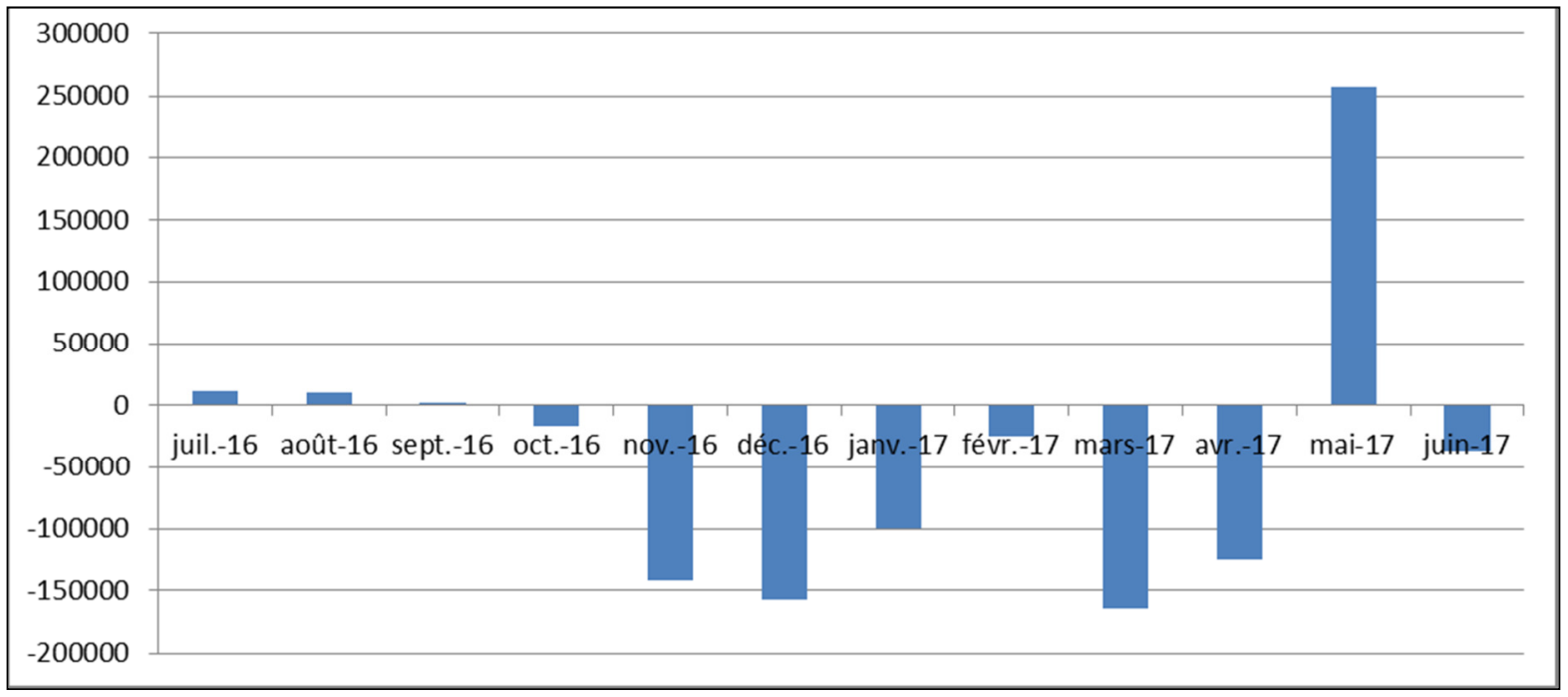

Figure 7. Monthly freshwater volume loss or gain between June 2016 and June 2017 in cubic meter on a $1 \mathrm{~km}$ coastline band.

\section{DISCUSSION AND CONCLUSIONS}

This is the first SMD network that has been installed in the Reunion Island. Since the beginning of the measurement period, more than $20000 \mathrm{EC} \operatorname{logs}$ have been recorded allowing to know SWI interface position on a 30 min basis.

These measurements have showed a $5,15 \mathrm{~m}$ rise of SWI position $(1 \mathrm{mS} / \mathrm{cm}$ limit $)$ between June 2016 and June 2017. Knowing the average porosity, water table elevation and SWI interface position it is possible to estimate available fresh groundwater volume. Along a 1 $\mathrm{km}$ band between extraction well and the Ocean, available fresh groundwater volume was found to be $1259000 \mathrm{~m} 3$ in June 2016. In June 2017, due to SWI progression this volume was found to be $777000 \mathrm{~m} 3$, that to say a $480000 \mathrm{~m} 3$ volume of freshwater replaced by brackish water.

In the Reunion Island, SMD network will now be spread to improve coastal extraction well management knowing SWI shape and position on a high frequency basis. 


\section{REFERENCES}

Aunay B, Broch d'Autelans R (2011) Montée du niveau marin induite par le changement climatique. Phase 1 - Diagnostic préalable aux conséquences sur l'intrusion saline dans les aquifères côtiers de La Réunion - Rapport final - BRGM/RP-59049-FR. BRGM, La Réunion

Bourhane A (2014) Méthodes d'investigation de l'intrusion marine dans les aquifères volcaniques : La Réunion et La Grande Comore. Thèse de Doctorat, Université de La Réunion

La Réunion. Rapp. BRGM/RP-63818-FR, 90p. BRGM, La Réunion 